\title{
Local anaesthesia as a standard of care for penetrating keratoplasty?
}

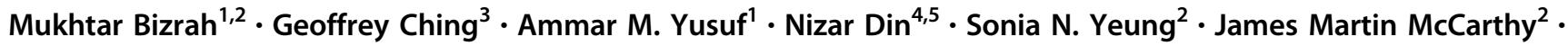 \\ Alfonso lovieno ${ }^{2} \cdot$ Simon P. Holland ${ }^{2}$
}

Received: 24 August 2020 / Revised: 2 April 2021 / Accepted: 25 May 2021 / Published online: 9 July 2021

(c) The Author(s), under exclusive licence to The Royal College of Ophthalmologists 2021

\begin{abstract}
Background/objectives To determine preferences in the use of local anaesthesia (LA) versus general anaesthesia (GA) for penetrating keratoplasty (PK), and to examine the safety of LA for PK.

Subjects/methods A retrospective analysis of PKs performed at an ophthalmology department in Canada from 01/01/2008 to 01/01/2020 was conducted to investigate rate of major complications. A questionnaire was also sent out to cornea specialists in the United Kingdom (UK) and Canada to determine trends in anaesthesia use for PK. Data on anaesthesia use in keratoplasty data was also obtained from the National Health Service Blood and Tissue (NHSBT) register.

Results The retrospective study found that 2143 PKs were performed under LA by 4 surgeons. The following complications were revealed: 1 acute anxiety attack with tachycardia, 3 extraocular myotoxicity cases requiring squint surgery, 1 expulsive suprachoroidal haemorrhage and 1 retrobulbar haemorrhage. The survey revealed $92 \%$ of cornea specialists in Canada preferred LA to GA. In the UK, $4.5 \%$ of specialists preferred LA, with most preferring GA due to suprachoroidal haemorrhage risk. NHSBT data revealed that 86.6\% of 6181 PKs performed in UK between 01/04/2015 and 31/03/2020 were done under GA.

Conclusions LA is preferred for PK in Canada, in contrast to the UK where GA is preferred. Our retrospective study suggests a low incidence of LA-related complications. We suggest that LA should be considered for most cornea transplant techniques, including optical penetrating keratoplasty. Rising worldwide keratoplasty numbers, ageing populations and risks of pandemics (e.g. COVID-19) give more reason for reduced reliance on GA.
\end{abstract}

\section{Introduction}

Diseases of the cornea are a leading cause of blindness globally. Since corneal transplantation (keratoplasty) was first performed more than 100 years ago; the number of keratoplasties has been observed to be rising globally [1-6].

Mukhtar Bizrah

m.bizrah@nhs.net

1 Imperial College Healthcare NHS Trust, Western Eye Hospital, London, UK

2 Department of Ophthalmology and Visual Sciences, University of British Columbia, Vancouver, BC, Canada

3 Faculty of Medicine, University of British Columbia, Vancouver, BC, Canada

4 Moorfields Eye Hospital NHS Foundation Trust, London, UK

5 Division of Ophthalmology and Visual Sciences, University of Toronto Toronto Western Hospital, 399 Bathurst St, Toronto, ON, Canada
Penetrating keratoplasty (PK) involves full-thickness trephination of the patient's cornea. This results in an open globe (so called 'open sky' procedure), until a new donor graft is sutured in place. There is an increased risk of intraocular bleeding and extrusion of intraocular contents [7]. This may be the reason that cornea surgeons may be more resistant to using local anaesthesia for a PK, as compared to lamellar (partial thickness) keratoplasties where the globe is closed.

Local anaesthesia (LA) has replaced general anaesthesia (GA) as the default anaesthesia choice for most anterior and posterior segment intraocular surgeries [8,9]. Retrobulbar (RB), peribulbar (PB) and sub-Tenon's (ST) blocks are forms of LA which provide both akinesia and anaesthesia, which are important for safe PK surgery $[7,10]$.

This study aims to examine the safety of LA (specifically: RB, PB and ST blocks) in PK, and whether it may be considered the standard of care. It consists of three parts:

1. A retrospective analysis of PKs performed under LA at Department of Ophthalmology and Visual Sciences (University of British Columbia). 
2. Analysis from National Health Service Blood and Tissue (NHSBT) and questionnaire results from UK and Canada cornea specialists.

3. Discussion including a literature review of safety of LA for PK.

\section{Materials and methods}

\section{Retrospective analysis}

The study was carried out at the Department of Ophthalmology and Visual Sciences at the University of British Columbia in Canada. The study was conducted in adherence with the principles of the Declaration of Helsinki. Ethical approval was granted by the Clinical Research Ethics Board of the University of British Columbia.

PKs performed from 01/01/2008 to 01/01/2020 at Mount Saint Joseph Hospital were reviewed for the occurrence of major complications relating to LA. Surgery was performed by a senior surgeon or a trainee in their team, the seniority of the primary surgeon was not recorded. Complications were pre-defined prior to the retrospective review of clinical notes, and were categorised as peri-operative or postoperative (Table 1). Of note, peri-operative complications included all complications occurring from the start of anaesthesia until return of the patient to the recovery room from surgery. A review of sedation and LA protocols was also performed.

Table 1 Pre-defined peri-operative and post-operative complications of local anaesthesia (LA) blocks.

\begin{tabular}{ll}
\hline Peri-operative complications & Post-operative complications \\
\hline $\begin{array}{l}\text { Retrobulbar haemorrhage } \\
\text { Suprachoroidal haemorrhage }\end{array}$ & $\begin{array}{l}\text { Permanent extraocular myotoxicity } \\
\text { Vision loss due to LA } \\
\text { Any other complication related to } \\
\text { LA or incomplete anaesthesia/ } \\
\text { akinesia of the eye }\end{array}$ \\
$\begin{array}{l}\text { Inability to perform surgery } \\
\text { due to LA }\end{array}$ \\
$\begin{array}{l}\text { Extrusion of intraocular } \\
\text { contents } \\
\text { Optic nerve damage } \\
\text { Oculocardiac reflex } \\
\text { Allergic reaction } \\
\text { Cardiovascular complications } \\
\text { Central nervous system } \\
\text { complications } \\
\text { Respiratory complications }\end{array}$ \\
\hline
\end{tabular}

\section{PK anaesthesia data}

Data was acquired from NHSBT on the use of local versus general anaesthetic in corneal transplantation [11]. The data, which was received on the 2nd July 2020, were collated for all cornea transplantations performed between 1st April 2015 and 31st March 2020.

\section{Questionnaire data}

A questionnaire was sent to practicing cornea specialists in the UK, in the following areas:

East Grinstead, Sussex
(a) Liverpool
(b) London
(c) Manchester
(d) Nottingham
(e) Southampton

Cornea specialists in each UK region were identified by searching each hospital department's website for cornea specialists, and by contacting ophthalmology departments' secretaries. Missing contact details for cornea specialists in the UK were obtained from the nhs.net directory search and online search for contact details on published research articles. The cornea fellow at Moorfield's eye hospital was also contacted to hand out a paper questionnaire to cornea specialists to maximise the response rate.

A register and contact details of practicing cornea specialists in Canada was obtained from the Canadian Ophthalmological Society and a questionnaire was emailed to them.

Three short questions were asked to the cornea specialists to maximise questionnaire response rates:

(1) Is local (LA) or general (GA) anaesthesia your default option for a standard penetrating keratoplasty operation?

(2) If LA is your preference, which type do you use (e.g. sub-Tenon's, peribulbar, etc)?

(3) If GA is your preference, why is this the case?

\section{Results}

\section{Retrospective analysis of penetrating keratoplasties}

Surgeons 1 and 2 started performing PKs before 2008, surgeon 3 started in 2012, and surgeon 4 started in 2017. In total, 2143 eyes underwent one of the following procedures by four surgeons: 
1. $\mathrm{PK}$ (primary or repeat)

2. PK (primary or repeat) with extracapsular lens extraction (ECCE) and intraocular lens (IOL) insertion

The number of corneal transplants performed by each surgeon (or their fellow/resident) are as follows:

1. Surgeon 1: $938 \mathrm{PKs}$ and $62 \mathrm{PKs}$ combined with ECCE and IOL insertion

2. Surgeon 2: $925 \mathrm{PKs}$ and $75 \mathrm{PKs}$ combined with ECCE and IOL insertion

3. Surgeon 3: $90 \mathrm{PKs}$ and $10 \mathrm{PKs}$ combined with ECCE and IOL insertion

4. Surgeon 4: $41 \mathrm{PKs}$ and 2 PKs combined with ECCE and IOL insertion

It was not possible to determine the exact number of surgeries performed by a trainee (resident or fellow) as opposed to the main surgeon as this is not documented. On questioning of the four surgeons, it is estimated that $50 \%$ of PKs were performed by a trainee.

The sedation protocols were: Patients undergoing keratoplasty are offered sedation. Patient who would like sedation are normally given $1 \mathrm{mg}$ of midazolam, with or without an analgesic agent (e.g. oral acetaminophen, intravenous fentanyl, etc). The maximum sedation permissible is $2 \mathrm{mg}$ of intravenous midazolam. In total, $2143 \mathrm{PKs}$ were performed either with or without ECCE and IOL insertion. The LA protocol was 3-7 $\mathrm{ml}$ of 50:50 lignocaine (2\%) and bupivacaine $(0.75 \%)$.

$6(0.28 \%)$ complications occurred out of a total of 2143 cases. Surgeon 1 had four complications, surgeon 2 had two complications and surgeons 3 and 4 had no LA-related complications.

The six complications were:

(a) three cases of inferior recti myotoxicity requiring squint surgery.

(b) one expulsive suprachoroidal haemorrhage ( $\mathrm{SCH}$ ).

(c) one retrobulbar haemorrhage.

(d) one case of tachycardia and severe acute anxiety, either due to intrathecal injection or a panic attack.

The three cases of inferior rectus muscle damage showed spontaneous improvement of double vision but did not achieve full resolution. Persistent double vision thus required treatment and were referred to the adult strabismus service. All three patients underwent squint surgery with resolution of symptoms.

The eye that developed a retrobulbar haemorrhage had no ocular nor systemic risk factors. There was no long-term effect on vision. Surgery was done successful under RB anaesthesia one month later. The eye with an expulsive $\mathrm{SCH}$ had very limited visual potential due to advanced glaucoma. The patient was of Far East Asian background and was noted to have a shallow orbit with narrow interpalpebral aperture. The expulsive $\mathrm{SCH}$ resulted in complete extrusion of the intraocular contents and the eye underwent subsequent evisceration.

One patient had tachycardia (heart rate $>110$ beats per minute) and severe acute anxiety within 5 min of a RB block, requiring urgent assessment by an anaesthetist. Surgery was not carried out. Anaesthetist assessment was not conclusive of a cause for this reaction. The two possible causes were intrathecal penetration of the LA, or a panic attack (patient has past medical history of severe anxiety).

\section{NHSBT findings}

The data acquired from NHSBT showed that $86.6 \%(5350 /$ 6181) of PKs carried out between 1 April 2015 and 31 March 2020 were carried out under GA. In contrast, 10.4\% (640/6181) of PKs in that same time frame were carried out under local anaesthesia. The remaining $3.1 \%$ of PKs were carried out under an unknown (not reported) method of anaesthesia (Table 2). Deep anterior lamellar keratoplasty (DALK) is often performed under a similar anaesthesia method as PK, because of the risk of conversion to PK during surgery. NHSBT data showed that $90.6 \%$ of 1954 DALKs were performed under GA, 6.3\% under LA and 3\% unreported anaesthesia choice. Of note, 6512 Descemet stripping automated endothelial keratoplasty (DSAEK) and 3,400 Descemet membrane endothelial keratoplasty (DMEK) operations were performed in this period. $33.5 \%$ of DSAEKs and $29.5 \%$ of DMEKs were performed under GA, and $64.1 \%$ of DSAEKs and $67.1 \%$ of DMEKs were performed under LA [11].

Table 2 Graft type and anaesthetic use for adult corneal transplants performed in the UK between 1 April 2015 and 31 March 2020 as of 2 July 2020 per National Health Service Bone and Transplant.

\begin{tabular}{lcccr}
\hline \multirow{3}{*}{ Graft Type } & Anaesthetic & & \\
\cline { 2 - 4 } & General & Local & Unknown & Total \\
\hline DSAEK & $2184(33.5 \%)$ & $4174(64.1 \%)$ & $154(2.4 \%)$ & 6512 \\
PK & $5350(86.6 \%)$ & $640(10.4 \%)$ & $191(3.1 \%)$ & 6181 \\
DMEK & $1002(29.5 \%)$ & $2282(67.1 \%)$ & $116(3.4 \%)$ & 3400 \\
DALK & $1771(90.6 \%)$ & $124(6.3 \%)$ & $59(3 \%)$ & 1954 \\
EK Unknown & $533(37.3 \%)$ & $867(60.7 \%)$ & $28(2 \%)$ & 1428 \\
Superficial & $94(69.1 \%)$ & $40(29.4 \%)$ & $2(1.5 \%)$ & 136 \\
lamellar & & & & \\
Other & $197(49 \%)$ & $180(44.8 \%)$ & $25(6.2 \%)$ & 402 \\
Unknown & $113(7 \%)$ & $56(3.5 \%)$ & $1440(89.5 \%)$ & 1609 \\
\hline
\end{tabular}




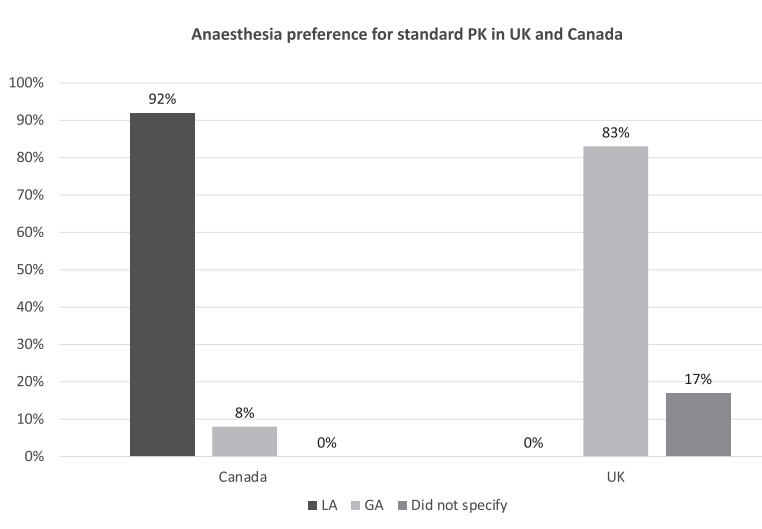

Fig. 1 Preference of anaesthesia choice for penetrating keratoplasty (PK) in the United Kingdom (UK) and Canada. Horizontal axis shows the type of anasthesia preferred by country (Canada vs UK). Vertical axis shows percentage of surgeons (from those surveyed).

\section{Questionnaire findings}

$23(68 \%)$ out of 34 UK specialists who were contacted completed the questionnaire. 38 (72\%) out of 53 cornea specialists in Canada completed the questionnaire. A provincial breakdown of these responses yielded that $4(11 \%)$ of the responses came from Alberta, $6(16 \%)$ from British Columbia, 1 (2.6\%) from Nova Scotia, 2 (5.3\%) from Manitoba, 14 (37\%) from Ontario, and 11 (29\%) from Quebec. Of the cornea specialists in the UK, 2 (8.7\%) practiced in East Grinstead, 13 (57\%) in London, 1 (4.3\%) in Liverpool, $3(13 \%)$ in Manchester, 2 (8.7\%) in Nottingham and $2(8.7 \%)$ in Southampton.

$35(92 \%)$ of 38 cornea specialists in Canada preferred the use of LA over GA. This contrasts with the UK, where 19 (83\%) of 23 specialists preferred to use GA (Fig. 1). The other $4(17 \%)$ specialists in the UK did not have a preference, but rather determined anaesthesia suitability on a case-by-case basis. All UK specialists preferred to use GA for younger patients.

$26(74 \%)$ of the 35 Canadian specialists who preferred local anaesthesia specified RB block to be their preferred method of LA for a standard PK. $3(8.6 \%)$ of the same population preferred one of a ST block, a PB block, or did not have a preference, but rather determined anaesthesia suitability on a case by case basis.

Figure 2 summarises the LA preferences. One of the surgeons who preferred RB anaesthesia additionally used sub-Tenon's anaesthesia if the former was found to provide inadequate akinesia or analgesia intraoperatively. 1 of 20 surgeons preferred to use RB anaesthesia in patients below 40 years of age, and ST anaesthesia in patients who are 40 years of age or above.

Although not directly enquired about in the questionnaire, five cornea specialists in Canada cited circumstances in which they would prefer the use of GA over LA.
Local anaesthesia preference in Canada for penetrating keratoplasty

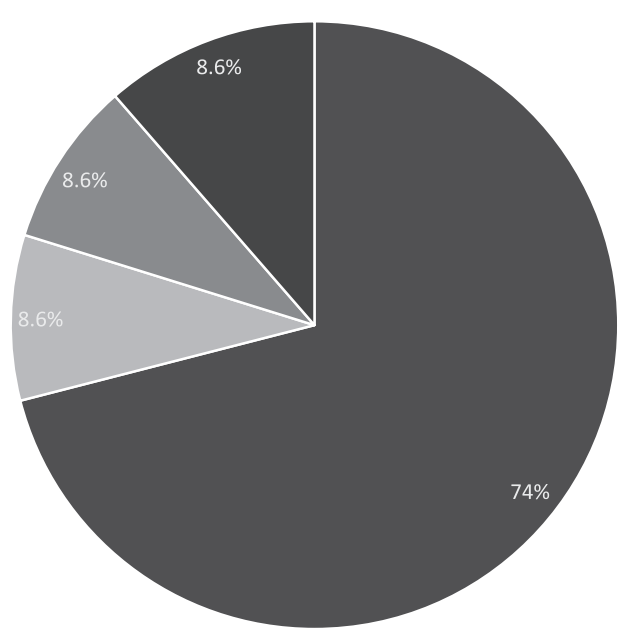

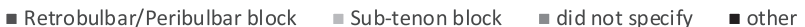

Fig. 2 Local anaesthesia (LA) preference of corneal specialists in Canada for penetrating keratoplasty (PK). This pie chart illustrates the percentage of surgeons in Canada preferring each type of local anaesthesia.

These reasons are patient anxiety, difficulty in positioning or maintaining patient position, intellectual/cognitive impairment, high risk of expulsive $\mathrm{SCH}$, or previous negative reactions due to LA.

Of the 19 UK specialists who preferred GA over LA, 18 stated higher intraoperative safety as the reason for their preference. One cornea specialist stated that they preferred GA because it was the standard anaesthesia used for a PK in the UK. 14 of these 19 UK surgeons specifically named a lower risk of expulsive $\mathrm{SCH}$ as their reason for preferring safety profile of GA. The other five surgeons preferred GA because it meant less concern about peri-operative movements and positive vitreous pressure.

Of the 12 UK corneal specialists who mentioned occasional use of LA, 1 preferred ST block, while 50\% (6/12) preferred PB block and 42\% (5/12) preferred RB block.

\section{Discussion}

The choice of LA versus GA for cornea transplantation is an important one for the patient, the surgeon and operating theatre staffing and efficiency. The more invasive the keratoplasty procedure (e.g. PK), the more controversial the choice of anaesthesia is expected to be. Rising cornea transplant numbers and ageing populations means choice of anaesthesia is critical [1-6]. In the era of the novel severe acute respiratory syndrome coronavirus 2 (SARS-CoV-2, 
Table 3 Comparison of reasons for choosing general anaesthesia (GA) over local anaesthesia (LA) for penetrating keratoplasty (PK) amongst cornea specialists in the United Kingdom (UK) and Canada.

\begin{tabular}{ll}
\hline Cornea specialists in UK & Cornea specialists in Canada \\
\hline Higher intraoperative safety & Patient anxiety \\
Lower risk of expulsive suprachoroidal haemorrhage & Difficulty positioning patient \\
Reduced positive vitreous pressure & Intellectual cognitive impairment \\
$\begin{array}{l}\text { Easier to administer systemic intraoperative medications (e.g. } \\
\text { muscle relaxants, hypotensive anaesthesia, mannitol) }\end{array}$ & High risk of expulsive \\
Young and/or anxious patient & Previous negative reaction to LA \\
Higher patient comfort and easier to position patient & \\
Most common practice nationwide & \\
\hline
\end{tabular}

disease now termed COVID-19) pandemic, anaesthesia choice has even more implications. Avoiding GA means avoiding intubation and other aerosol generating procedures, which can increase risk of nosocomial transmission to healthcare staff during viral pandemics [12].

LA has the advantages of time efficiency, being less labour intensive, less costly, and does not require fasting. There are circumstances in which GA is the better or only suitable option. This includes significant patient anxiety, difficulty in positioning patient or maintaining position, intellectual/cognitive impairment, high risk of expulsive $\mathrm{SCH}$, or previous negative reactions to LA. GA may also be more suitable for complex cases (e.g. combined surgeries) in which the patient is expected to lie still for more than $2 \mathrm{~h}$.

The retrospective review of PK surgeries by four surgeons in BC revealed a low incidence $(0.28 \%)$ of serious complications. It is noteworthy that only one expulsive SCH occurred, with no evidence of a link to use of LA. Expulsive $\mathrm{SCH}$ is the most common complication cited by UK specialists in our questionnaire as the reason for avoiding LA. However, the rate of expulsive $\mathrm{SCH}$ in our study is one of the lowest in the published literature (see below) [7]. This is despite the PKs being done under LA. 3 cases of extraocular myotoxicity occurred, requiring surgical intervention for full resolution. A review of causes [10] [13] of this is beyond the scope of this study. Patients in our study had RB blocks injected through the classic 'Atkinsons' insertion site; at the inferotemporal margin of the orbit. Risk of this complication may be reduced by adjusting needle insertion site to be more lateral [10]. Of note, since adding hyaluronidase to our standard LA mixture, this complication has not occurred. Hyaluronidase may reduce the risk of extraocular myotoxicity, as well as other LArelated adverse events [13].

As a retrospective study, it was not possible to assess the efficacy of anaesthesia, or how many injections were required to achieve adequate anaesthesia and akinesia. This is a weakness of this study. However, all PKs were successfully completed without having to induce GA for any patient, indicating efficacy of LA for this procedure. The Ophthalmic Mutual Insurance Company, who provide cover for ophthalmologists nationwide in the USA, reported four deaths from GA and two deaths from brainstem anaesthesia in insurance claims from ocular injury related to anaesthesia [14].

The level of sedation required for a PK is an important in the context of LA. In our experience, deep sedation may result in snoring and sudden movement due to waking up. None of the patients in our retrospective study received more than $2 \mathrm{mg}$ of intravenous midazolam. The level of sedation is thus conservative, and patients are conscious. Although there is continuous respiratory and cardiovascular monitoring, heavy sedation is not administered in our department. This is because all sedation is administered by a trained nurse with no anaesthetist supervision. Analgesics can also be used, due to reported benefit in combination with sedation in ophthalmic surgery [15]. Deep sedation is not however a requirement for performing cornea transplantation under LA.

Another important aspect of LA is that lid and orbicularis akinesia are not always fully achieved with LA (PB, RB or ST blocks). In the authors' experience, this is usually achieved well when the block is performed correctly (adequate LA quantity and injected into correct anatomical space). If this is not the case, then more LA is injected to achieve this, and block given time to reach this effect (at least $15 \mathrm{~min}$ ). Another option is to perform a facial nerve block to enable orbicularis akinesia, which is important in open globe surgery, particularly high-risk PK.

Both Canada and the UK are higher income countries, both offer publicly funded healthcare, and are part of the Commonwealth of Nations. One may therefore not expect a substantial variance in anaesthesia choice for one of the most common cornea surgeries. It is noteworthy that PK is an established procedure, and was first successfully performed in 1906 [16]. A similarity in evolution of anaesthesia use for PK may therefore be expected. Interestingly, Canada and UK specialists cite the same reasons for choosing to do a PK under GA (Table 3). These findings are suggestive of personal preference rather than evidencebased information in determining anaesthesia choice. This may be explained by less robust research (see below) into 
anaesthesia interventions in PK as compared to other surgical specialties [17-20].

Our retrospective analysis at UBC and the questionnaire show that the large majority of Canadian cornea specialists prefer LA. This contrasts with the NHSBT data which shows that $86.6 \%$ of PKs performed between April 2015 to March 2020 were done under GA. This correlates with the questionnaire findings showing that $83 \%$ of UK specialists prefer GA. This is a striking difference considering that different forms of anaesthesia have different complication profiles. We consider NHSBT to be highly representative of cornea practice in the UK as this is the only source of cornea grafts nationally. A few centres import cornea grafts from abroad when there is a shortage of tissue. Notably, NHSBT data indicates that GA was also used for approximately a third of endothelial (DMEK and DSAEK) keratoplasties. There appears to be equivocal safety and efficacy of LA versus GA in endothelial keratoplasty [21]. Although large comparative trials are needed, one would expect LA to be safer in endothelial keratoplasty than PK due to avoidance of an open globe ('open sky'). Interestingly, GA has been reported as the preferred technique for keratoplasty by 93\% of ophthalmologists in the UK since the 1990s [22]. We hypothesise that there are adequate number of ophthalmology operating theatre lists with anaesthetist cover in the UK, which may lead to cornea specialists feeling that use of LA is non-justifiable. If most surgeons perform PK under GA, this may be considered to be the standard of care. The use of LA may have not therefore been explored by UK specialists due to concerns about medico-legal implications. For example, if a UK specialist was to have a major complication during a PK under LA, he or she may be criticised or unsupported by colleagues regarding the anaesthesia choice. Less experience with RB/PB blocks in PK surgery understandably leads to the concerns about extrusion of intraocular contents and $\mathrm{SCH}$. In our experience and others $[7,23,24]$, more than $3-6 \mathrm{ml}$ of LA for a PB or RB block is rarely needed. It is therefore unexpected to result in significantly increased posterior vitreous pressure. It is important to administer pressure (e.g. Honan balloon) on the globe after a local block to reduce intraocular pressure and positive vitreous pressure [25].

In Canada, few ophthalmology surgical lists have anaesthetist cover. Most specialists use LA as a result, and may have had most surgical training in cornea transplantation done using LA. This may explain why their preference is for LA. If there were more surgical lists with anaesthetist cover, more specialists may have preferred GA.

LA has good efficacy and safety in PK. In a study of 16,224 patients undergoing ophthalmic surgery, $95 \%$ of patients achieved $95 \%$ or more degree of akinesia with $\mathrm{PB}$ anaesthetic administered by surgeons, anaesthetists or nurses [26]. In another prospective study of 137 consecutive keratoplasties, $100(73 \%)$ were performed under PB anaesthesia [27]. 80\% achieved complete akinesia, and 94\% of patients found the procedure to be painless. Surgical conditions were reported as optimal by the surgeon in $98 \%$ of cases, and $98 \%$ of patients found PB anaesthesia satisfactory or very satisfactory. One eye $(1 \%)$ had a severe intraoperative non-expulsive $\mathrm{SCH}$. In another prospective study of 136 PK patients, 124 (91\%) underwent PB (5 ml) anaesthesia [24]. Most PKs were combined with other procedures $(60.5 \%)$, and $7.2 \%$ overall required intravenous sedation. No information on oral sedation was given. $92 \%$ had adequate akinesia after 1st PB injection, and $97 \%$ of patients were satisfied with analgesia. $5 \%$ developed positive intraocular pressure and $4 \%$ developed chemosis. The surgery was completed successfully in all cases, and no cases of SCH were reported. In another prospective study, Wang et al. compared LA with GA for 141 optical and therapeutic PKs [23]. All of the intraoperative complications, namely extrusion of intraocular contents and iris prolapse, occurred in the eyes that underwent therapeutic (not optical) PK under LA. No SCH was reported in any of the cases. Relapse rate for fungal keratitis in this group was $13 \%$, compared to GA in which relapse did not occur. There was no increased risk of intraoperative complications in LA versus GA in patients undergoing an optical PK.

In a case series of 2011 eyes that underwent PKs, expulsive $\mathrm{SCH}$ occurred in $0.45 \%$. There was no difference in rate of expulsive SCH between LA and GA [28]. The incidence of SCH was significantly higher in eyes with preoperative anterior chamber IOLs than any other condition. In another study of $830 \mathrm{PKs}, 9(1.08 \%)$ had a massive $\mathrm{SCH}$ [29]. 4 out of 714 PKs done under GA had a SCH, compared to 5 out of 116 PKs done under RB block. It was not known why the rate was higher in LA patients. Seven of the nine eyes had open posterior capsules, and were either aphakic (four eyes) or had an anterior chamber IOL (three eyes). In a larger case series of 2412 PKs, incidence of expulsive $\mathrm{SCH}$ was $0.1 \%$. $2298 \mathrm{PKs}$ were done under GA, and 123 were done under LA. All expulsive SCH occurred under GA [30]. In another case series of 543 cases that underwent PK for optical improvement, 4 eyes $(0.73 \%)$ developed an intraoperative $\mathrm{SCH}$. Of these, the two that had GA had an expulsive SCH and the two (50\%) that had PB anaesthesia had a non-expulsive massive $\mathrm{SCH}$ [7].

A RB block is often regarded as higher risk form of anaesthesia than a PB block. However, both techniques have been found to be equally efficacious in cataract surgery, with rare and equivalent risks of severe complications [31]. As far as we know, there are no trials comparing the efficacy and safety of different forms of LA for PKs. This is an area which may benefit from future clinical trials.

In conclusion, increasing demand and evolution of keratoplasty techniques have contributed to rising numbers of 
corneal transplants globally [1-6]. There is evidence in the literature to suggest the safety of LA in endothelial keratoplasty [21], but little data exist on penetrating keratoplasty. The results of our study, the questionnaire of cornea specialists and literature review support consideration of LA as a standard rather than an exceptional anaesthetic choice for penetrating keratoplasty. Moreover, patients who are systemically not fit for GA should not be excluded from having a PK under LA if this intervention is needed. In the era of the COVID-19 pandemic due to SARS-CoV-2, the findings of this study bear even more relevance. Avoiding GA means avoiding intubation and other aerosol generating procedures, which can increase risk of nosocomial transmission to healthcare staff during viral pandemics [12].

We suggest LA as an effective and safe anaesthesia choice for primary or repeat penetrating keratoplasty, particularly optical penetrating keratoplasty.

\section{Summary}

\section{What was known before}

- There is limited data about the safety and efficacy of local anaesthesia for penetrating keratoplasty.

\section{What this study adds}

- Local anaesthesia has good safety and efficacy profile in penetrating keratoplasty.

- We suggest that local anaesthesia should be considered for most corneal transplantation, including optical penetrating keratoplasty.

\footnotetext{
Acknowledgements Mukhtar Bizrah would like to thank the T.F.C. Frost Charitable Trust for being the major fund provider of his cornea fellowship at UBC. He would also like to thank the HCA International Foundation, the Royal Society of Medicine and the Royal College of Ophthalmologists for their travelling scholarship awards. We wish to thank all the cornea specialists who contributed information about their PK anaesthesia techniques, to further our understanding of practice trends.
}

Author contributions $\mathrm{MB}, \mathrm{AI}$ and $\mathrm{SH}$ conceived of and designed this study. GC, ND, AY, and MB gathered the data and performed statistical analyses. $\mathrm{MB}$ and $\mathrm{GC}$ contributed to the writing of the manuscript. All authors reviewed the manuscript, edited it and approved it.

\section{Compliance with ethical standards}

Conflict of interest MB: None. GC: None. AMY: None. ND: None. SNY: None. JMM: None. AI: None. SPH: Lecturer for Schwind and consultant for Novartis.
Publisher's note Springer Nature remains neutral with regard to jurisdictional claims in published maps and institutional affiliations.

\section{References}

1. Droutsas K, Bagikos G, Miltsakakis D, Georgalas I, Lazaridis A, Chatzistefanou K, et al. Trends in indications and techniques of corneal transplantation from 1999 through 2015 at a tertiary referral center in Athens, Greece. J Ophthalmol [Internet]. 2018;2018:9132083. http://www.ncbi.nlm.nih.gov/pubmed/30079255. Accessed 17 Apr 2020.

2. Flockerzi E, Maier P, Böhringer D, Reinshagen H, Kruse F, Cursiefen C, et al. Trends in corneal transplantation from 2001 to 2016 in Germany: a report of the DOG-section cornea and its keratoplasty registry. Am J Ophthalmol [Internet] 2018;188:91-8. http://www. ncbi.nlm.nih.gov/pubmed/29410297. Accessed 17 Apr 2020.

3. Tan JCH, Holland SP, Dubord PJ, Moloney G, McCarthy M, Yeung SN. Evolving indications for and trends in keratoplasty in British Columbia, Canada, from 2002 to 2011: a 10-year review [Internet]. Cornea. 2014;33:252-6. http://www.ncbi.nlm.nih.gov/ pubmed/24457452. Accessed 19 Apr 2020.

4. Almeida HG, Kara-José N, Hida RY, Kara-Junior N. A 15-year review of corneal transplant in Brazil. Eye Contact Lens. 2018;44: S376-81.

5. Kim BZ, Meyer JJ, Brookes NH, Moffatt SL, Twohill HC, Pendergrast DG, et al. New Zealand trends in corneal transplantation over the 25 years 1991-2015. Br J Ophthalmol. 2017;101:834-8.

6. Keenan TDL, Carley F, Yeates D, Jones MNA, Rushton S, Goldacre MJ. Trends in corneal graft surgery in the UK. Br J Ophthalmol [Internet]. 2011;95:468-72. http://www.ncbi.nlm.nih. gov/pubmed/20584718. Accessed 18 Apr 2020.

7. Bandivadekar P, Gupta S, Sharma N. Intraoperative suprachoroidal hemorrhage after penetrating keratoplasty: case series and review of literature [Internet]. Eye Contact Lens. 2016;42:206-10. http://www.ncbi.nlm.nih.gov/pubmed/25996421. Accessed 18 Apr 2020.

8. Theventhiran A, Shabsigh M, De Moraes CG, Cioffi GA, Kamel M, Blumberg D. et al. A comparison of retrobulbar versus topical anesthesia in trabeculectomy and aqueous shunt surgery. J Glaucoma [Internet]. 2018;27:28-32. Accessed 18 Apr 2020.

9. Sallam AAB, Donachie PHJ, Williamson TH, Sparrow JM, Johnston RL.The Royal College of Ophthalmologists' National Ophthalmology Database Study of vitreoretinal surgery: report 5, anaesthetic techniques. $\mathrm{Br} \mathrm{J}$ Ophthalmol [Internet]. 2016;100: 246-52. http://www.ncbi.nlm.nih.gov/pubmed/26142401.

10. Jaichandran V. Ophthalmic regional anaesthesia: a review and update. Indian J Anaesth [Internet]. 2013;57:7. http://www.ijaweb. org/text.asp?2013/57/1/7/108552. Accessed 18 Apr 2020.

11. NHSBT. Anaesthetic Use. Bristol: NHSBT; 2021.

12. Odor PM, Neun M, Bampoe S, Clark S, Heaton D, Hoogenboom EM, et al. Anaesthesia and COVID-19: infection control. Br J Anaesth [Internet]. 2020. https://bjanaesthesia.org/article/S00070912(20)30200-2/fulltext. Accessed 19 Apr 2020.

13. Rüschen $\mathrm{H}$, Aravinth $\mathrm{K}$, Bunce $\mathrm{C}$, Bokre D. Use of hyaluronidase as an adjunct to local anaesthetic eye blocks to reduce intraoperative pain in adults [Internet]. Cochrane Database Syst Rev. 2018;2018:CD010368. http://www.ncbi.nlm.nih.gov/pubmed/ 29498413. Accessed 18 Apr 2020.

14. Morley M, Menke AM, Nanji KC. Ocular anesthesia-related closed claims from ophthalmic mutual insurance company 2008-2018. Ophthalmology. 2020;127:852-8. 1

15. Cok OY, Ertan A, Bahadir M. Remifentanil versus fentanyl in combination with midazolam for retrobulbar block in cataract 
surgery. Saudi Med J [Internet]. 2008;29:544-8. http://www.ncbi. nlm.nih.gov/pubmed/18382796. Accessed 18 Apr 2020.

16. Zirm E. Eine erfolgreiche totale Keratoplastik. Albr von Græfe's Arc Ophthalmol [Internet]. 1906;64:580-93. http://link.springer. com/10.1007/BF01949227. Accessed 18 Apr 2020.

17. Harky A, Chan JSK, Kot TKM, Sanli D, Rahimli R, Belamaric $\mathrm{Z}$, et al. General anesthesia versus local anesthesia in carotid endarterectomy: a systematic review and meta-analysis. J Cardiothorac Vasc Anesthesia [Internet]. 2020;34:219-34. http://www.ncbi.nlm.nih.gov/pubmed/31072705. Accessed 18 Apr 2020

18. Afolabi BB, Lesi FEA. Regional versus general anaesthesia for caesarean section. Cochrane database Syst Rev [Internet]. 2012;10:CD004350. http://www.ncbi.nlm.nih.gov/pubmed/ 23076903. Accessed 18 Apr 2020.

19. Matharu GS, Garriga C, Rangan A, Judge A. Does regional anesthesia reduce complications following total hip and knee replacement compared with general anesthesia? An analysis from the National Joint Registry for England, Wales, Northern Ireland and the Isle of Man. J Arthroplasty. 2020;35:1521-28.e5.

20. Hajibandeh S, Hajibandeh S, Mobarak S, Bhattacharya P, Mobarak D, Satyadas T. Meta-analysis of spinal anesthesia versus general anesthesia during laparoscopic total extraperitoneal repair of inguinal hernia. Surg Laparosc Endosc Percutan Tech [Internet]. 2020. http://www.ncbi.nlm.nih.gov/ pubmed/32217883. Accessed 18 Apr 2020.

21. Rickmann A, Andres C, Boden K, Wahl S, Szurman P. Analysis of different types of anesthesia in descemet membrane endothelial keratoplasty. Int Ophthalmol [Internet]. 2020;40:541-5. http://www.ncbi.nlm.nih.gov/pubmed/31768812. Accessed 18 Apr 2020.

22. Burdon MA, McDonnell P. A survey of corneal graft practice in the United Kingdom. Eye. 1995;9:S6-S12. (6 SUPPL.)
23. Wang X, Dang GF, Li YM, Li WF, Wu XY. General anesthesia versus local anesthesia for penetrating keratoplasty: a prospective study. Int J Ophthalmol. 2014;7:278-82.

24. Agrawal V, Tharoor M. Peribulbar anaesthesia for penetrating keratoplasty. A case series. Indian J Ophthalmol [Internet]. 2002;50:313-6. http://www.ncbi.nlm.nih.gov/pubmed/12532497. Accessed 18 Apr 2020.

25. Ling R, Beigi B, Quinn A, Jacob J. Effect of Honan balloon compression on peribulbar anesthesia adequacy in cataract surgery. J Cataract Refract Surg [Internet]. 2002;28:113-7. http://www.ncbi. nlm.nih.gov/pubmed/11777719. Accessed 18 Apr 2020.

26. Davis DB, Mandel MR. Efficacy and complication rate of 16,224 consecutive peribulbar blocks: a prospective multicenter study. J Cataract Refract Surg. 1994;20:327-37.

27. Muraine M, Calenda E, Watt L, Proust N, Cardon A, Eupherte L, et al. Peribulbar anaesthesia during keratoplasty: a prospective study of 100 cases. Br J Ophthalmol. 1999;83:104-9.

28. Price FW, Whitson WE, Ahad KA, Tavakkoli H. Suprachoroidal hemorrhage in penetrating keratoplasty. Ophthalmic Surg [Internet]. 1994;25:521-5. http://www.ncbi.nlm.nih.gov/pubmed/ 7970534. Accessed 18 Apr 2020.

29. Ingraham HJ, Donnenfeld ED, Perry HD. Massive suprachoroidal hemorrhage in penetrating keratoplasty. Am J Ophthalmol. 1989;108:670-5.

30. Groh MJM, Seitz B, Händel A, Naumann GOH. Expulsive blutung bei der perforierenden keratoplastik-Inzidenz und risikofaktoren. Klin Monbl Augenheilkd [Internet]. 1999;215: 152-7. http://www.ncbi.nlm.nih.gov/pubmed/10528279. Accessed 18 Apr 2020

31. Alhassan MB, Kyari F, Ejere HOD. Peribulbar versus retrobulbar anaesthesia for cataract surgery. Cochrane Database Syst Rev. [Internet]. 2015;2015:CD004083. http://www.ncbi.nlm.nih.gov/ pubmed/26133124. Accessed 18 Apr 2020. 